\title{
Oxygen barrier property of polypropylene-polyether treated clay nanocomposite
}

\author{
M. Pannirselvam ${ }^{*}$, A. Genovese ${ }^{2}$, M. C. Jollands ${ }^{1}$, S. N. Bhattacharya ${ }^{1}$, R. A. Shanks ${ }^{2}$ \\ ${ }^{1}$ Rheology and Material Processing Centre, School of Civil, Environmental and Chemical Engineering, RMIT University, \\ Melbourne, Australia \\ ${ }^{2}$ School of Applied Sciences, RMIT University, Melbourne, Australia
}

Received 28 November 2007; accepted in revised form 23 April 2008

\begin{abstract}
Polypropylene (PP) nanocomposites were obtained by solution blending of polyether treated montmorillonite and PP, with a coupling agent of maleic anhydride grafted polypropylene (PP-g-MA). The composition of the inorganic clay was varied in 1, 2 and $5 \mathrm{phr}$ (parts of clay per hundred of PP by mass) while films of the composites were obtained via compression molding. Wide-angle X-ray scattering (WAXS) showed nanocomposites in which silicate layers were exfoliated and intercalated with respect to the different clay ratios. The morphology and gas permeability of hybrids prepared with organoclay were compared. Morphological studies using transmission electron microscopy showed most clay layers were dispersed uniformly in the PP matrix. Some tactoids of agglomerated nanoparticles were detected, as clay content increased. The oxygen permeability for all the hybrids for clay loadings were reduced by $30 \%$ of the corresponding values for pure PP.
\end{abstract}

Keywords: nanocomposites, polyether treated clay, surfactants, oxygen barrier properties, gas tortuous path theory

\section{Introduction}

Polypropylene (PP) is one of the fastest growing commercial thermoplastics due to its attractive combination of low density and high heat distortion temperature $[1,2]$. There are some limitations in physico-chemical properties that restrict PP applications.

A typical illustration is in packaging, where PP has poor oxygen gas barrier resistance [3, 4]. No single polymer has shown the ideal combination of performance features. PP possesses good water vapour barrier properties, but it is easily permeated by oxygen, carbon dioxide, and hydrocarbons. The necessity of developing more effective barrier polymers has given rise to different strategies to incorporate and optimize the features from several components. Most schemes to improve PP gas barrier properties involve either addition of higher barrier plastics via a multilayer structure (co-extrusion) or by introducing filler with high aspect ratio in the polymer matrix. 1. Co-extrusion allows tailoring of film properties through the use of different materials where each material component maintains its own set of properties, compared with blending of polymers in a mono-extrusion technique. Co-extrusion is used to generate multilayer laminate structures from separately extruded polymer films that are sandwiched together $[3,4]$. Resulting films may comprise many layers, such as the PP-adhesivepoly(ethylene-co-vinyl alcohol) (EVOH)-adhesive PP system: EVOH barrier sheet trapped between two layers of moisture resistant PP and two additional adhesive strata. However, by nature coextrusion is a complex and expensive process. 
2. Alternatively, nano-fillers with high aspect ratio can be loaded into the polymer matrix. Polymer nanocomposites are a better choice with significant property increments from clay materials [1-4]. Lange et al. mentioned in review that nanocomposite materials are one of the methods for improving gas barrier properties of polyolefins [5]. Recent developments in polymer nanocomposites have attracted attention due to the possibilities offered by this technology to enhance the barrier properties of inexpensive commodity polymers. Many studies have demonstrated improvements in permeability reduction to gases, moisture and organic vapours resulting from the addition of low concentrations of layered clay nanoparticles to various thermoplastic matrices [6-8]. Nanoparticles have been shown to influence the properties of the polymers at low volume fractions [9]. This is mainly due to their nanometer scale particle size and intraparticle distances. The desired properties are usually reached at low filler volume fraction, allowing the nanocomposites to retain macroscopic dispersion and low density of the polymer. The geometrical shape of the particle plays an important role in determining the properties of the composites [10]. There is $40 \%$ reduction in oxygen permeability upon the incorporation of $4 \%$. vol organoclay into polyethylene, as reported by Osman et al. [8,9]. Avella et al. suggested that the calcium carbonate nanoparticles drastically reduced the permeability of oxygen and carbon dioxide for PP nanocomposites [11]. Yano et al. obtained a 10-fold reduction in the water vapour permeability coefficient of a polyimide containing $2 \% \mathrm{wt}$ mica nanoparticles in comparison with the unfilled polymers [12]. The improved nanocomposite barrier behaviour illustrated by these examples has been explained by the tortuous path model, in which the presence of impermeable clay platelets generates an overlapped structure that hinders penetrant diffusion and thus decreases the permeability of the material $[3,10]$.

\section{Benefits and challenges with smectite clays}

Of all dioctahedral smectities, montmorillonite (MMT) is mainly used in nanocomposites. The choice of MMT as a sorbent of organic compounds is influenced by its large surface area to mass $\left(760 \mathrm{~m}^{2} / \mathrm{g}\right)$, its high cation exchange capacity, largely independent of salt concentrations and $\mathrm{pH}$, and the relative ease by which it forms an interlayer complex with a wide variety of organic molecules $[13,14]$. Dimorphic clays are formed by condensation in a 1:1 proportion and trimorphic clays (three sheets) are formed by 2:1 condensation, with the octahedral sheet being sandwiched between two sheets of inward-pointing tetrahedra. The challenge with montomorillonite clay is its incompatibility with organic polymers. The silicate layers of the clay are 'incompatible' with organic polymers, due to surface hydroxyl groups; the smectite clays are usually treated to make them hydrophobic by ionexchange of the sodium interlayer cations with long-chain alkyammonium cations [2, 15]. Instability of ammonium salts at temperatures encountered in melt mixing greater than $200^{\circ} \mathrm{C}$ leads to discolouration of the polymer matrix [2, 16, 17]. Hoffmann elimination can occur under basic conditions; for instance in the presence of sodium hydroxide, quaternary ammonium salts decompose by Hoffmann elimination, yielding the corresponding trialkyl amine and an alkene [16-18, 26] (Figure 1). Crown ethers and cryptands are more expensive than all other intercalants; however they are stable under higher temperatures up to $200^{\circ} \mathrm{C}$ [19]. Poly(ethylene glycol) (PEG) is more stable than quaternary ammonium salts, but of lower activity. Polyether compounds as intercalants can act as ligands of these interlayer sodium cations, giving rise to stable complexes. PEG treated clay is thermally stable to $327^{\circ} \mathrm{C}$ in an inert atmosphere and $275^{\circ} \mathrm{C}$ in air [20-22]. These above mentioned advantages appeal to the use of poly(ethylene glycol) monolau-

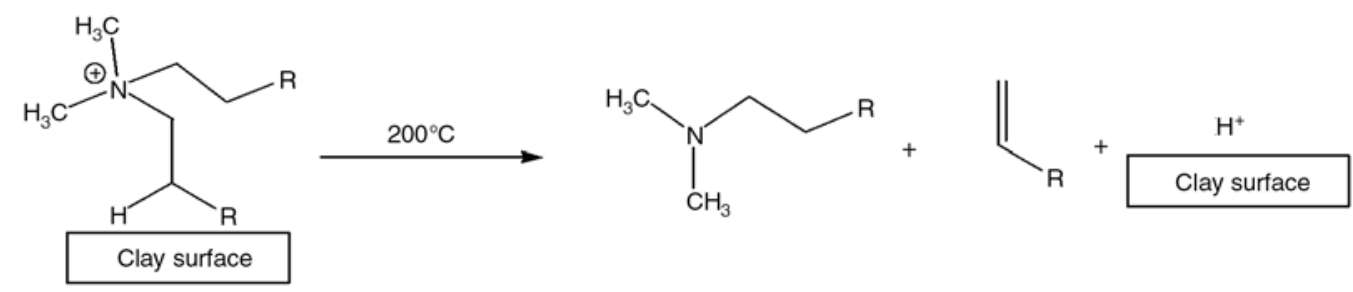

Figure 1. Mechanism of Hoffmann degradation in organoclays 


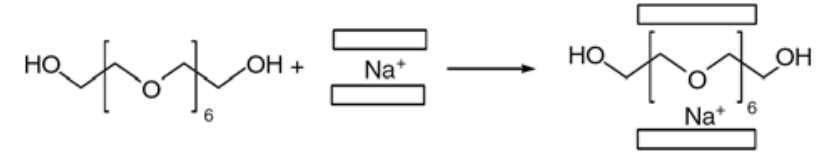

Figure 2. Mechanism of intercalation of poly(ethylene glycol) with sodium montmorillonite

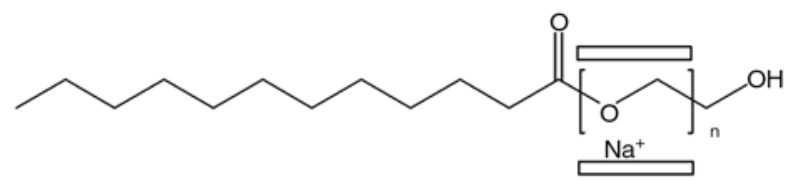

Figure 3. Product of reaction between poly(ethylene glycol) monolaurate and untreated clay

rate (PEG-ML) as an alternative intercalant, to conventional alkyl amine chain for surface treatment of clay. In this research, montmorillonite clay was treated with PEG-ML. Treated clay provided increased d-spacing $(1.82 \mathrm{~nm})$ that resulted from complexation between PEG oxygen atoms and sodium ions between the clay platelets (Figure 2).

Clay was treated with various intercalants that provided different d-spacing. The added advantage of treating clay with PEG-ML was its long alkyl chain (Figure 3) that could interact with PP. The effect of reinforcement of PP by layered silicate was determined by at least two important factors: clay dispersion (exfoliation or intercalation) and interaction between clay and PP. Many researchers mentioned that it is difficult for PP or other polyolefins to adhere to polar materials [2, 10, 23]. Interfacial agents play an important role in overcoming this difficulty. In order to overcome this challenge in trial experiments with this treated clay, maleic anhydride grafted polypropylene (PP-gMA) was used as a compatibilizer [24]. PP-g-MA reacted with $-\mathrm{OH}$ groups on the clay surface, increasing the compatibility between clay and PP. The aim of this research is to synthesize PP nanocomposites with PEG-ML treated clay, using a solution blending technique. Oxygen barrier of the nanocomposites and pure PP were compared, in addition to structural characterization to validate the dispersion of clay layers in polymer matrix.

\section{Experimental}

\subsection{Treatment of clay with poly(ethylene glycol) monolaurate}

Sodium montmorillonite $\left(\mathrm{Na}^{+-} \mathrm{MMT}\right)$ was purchased from Southern Clay Products, Texas, USA.
Cation exchange capacity of the clay was $92.6 \mathrm{meq} / 100 \mathrm{~g}$ clay. Poly(ethylene glycol) $\left(M_{n}=\right.$ $400 \mathrm{~g} / \mathrm{mol}$ ) monolaurate were purchased from Sigma-Aldrich Chemicals and used as received. Clay was preheated in vacuum oven for $8 \mathrm{~h}$ at $70^{\circ} \mathrm{C}$ for removal of moisture [26]. The nature of solvents is critical to facilitate the insertion of organic materials (in this case: PEG-ML between the silicate layers, the polarity of the medium being a determining factor for intercalations. Preheated clay was dispersed in water at $3 \%$ concentration and heated to $75^{\circ} \mathrm{C}$ for $3 \mathrm{~h}[19,25]$. The amount of intercalant was calculated according to cation exchange capacity of $\mathrm{Na}^{+-} \mathrm{MMT}$ (cation exchange capacity of clay $=92.6 \mathrm{meq} / 100 \mathrm{~g}$ of clay). After careful addition of intercalants, the contents of the beaker were heated to $70^{\circ} \mathrm{C}$ for $3 \mathrm{~h}$. The contents were cooled and filtered under vacuum. The filter cake was vacuum dried at $60^{\circ} \mathrm{C}$ and then the intercalated clay was dried in oven. The dried clay was ground using a mortar and pestle for uniformity in grain size. The treated clay was analysed using wide-angle X-ray scattering (WAXS) and thermogravimetry (TG). Results of WAXS and TG are reported elsewhere [26].

\subsection{Preparation of nanocomposites}

Clay treated with PEG-ML was added to PP as filler. Clay treated with PEG 400 monolaurate is abbreviated as PEGC. PP $\left\{M_{w}=250000 \mathrm{~g} / \mathrm{mol}\right.$, $T_{m}=167^{\circ} \mathrm{C}$, density $=0.905 \mathrm{~g} / \mathrm{cm}^{3}$ (ASTM D1505), MFI $=11 \mathrm{dg} / \mathrm{min}$ (ASTM D1238) $\}$ were obtained from Basell Australia. PP-g-MA $\left\{T_{m}=152^{\circ} \mathrm{C}\right.$, $0.6 \%$ wt MA $\}$ was supplied by Sigma-Aldrich chemicals. All chemicals and polymers used in this research were commercial products and they were used as received without further purification. The preparation of the nanocomposites was carried out by a solution blending method using o-xylene [27-29]. The amount of treated clay added was 1,2 and 5 parts per hundred (phr) of the total weight of PP and PP-g-MA. The process of preparation of nanocomposites can be divided into the following three steps:

Step 1: Dispersion of PEGC in o-xylene in order to minimize agglomeration of clay layers and cluster formation. Calculated amounts of treated clay were added to $50 \mathrm{ml}$ of o-xylene solution. This solution was sonicated using a probe sonicator (High Inten- 
Table 1. Proportion of PP, PP-g-MA (as compatiblizer), and PEGC for the preparation of nanocomposites

\begin{tabular}{|l|c|c|c|}
\hline Identification & PP [\%·wt] & PP-g-MA [\%·wt] & Clay [phr] \\
\hline PP & 100 & - & - \\
\hline PP-PEGC1 & 90 & 10 & 1 \\
\hline PP-PEGC2 & 90 & 10 & 2 \\
\hline PP-PEGC5 & 90 & 10 & 5 \\
\hline
\end{tabular}

sity Ultrasonic Processor, Model: GEX 500) to induce an efficient dispersion of nanoclay.

Step 2: The PP and compatibilizer PP-g-MA were dissolved in o-xylene, composition reported in Table 1. This mixture was stirred continuously for $6 \mathrm{~h}$ until the PP dissolved.

Step 3: Thorough dispersion of the solutions prepared in the first and second stages of this process were performed using an Ultraturrax high-shear disperser. The dispersion was carried out at $150^{\circ} \mathrm{C}$ for $10 \mathrm{~min}$. The product was separated by precipitation in cold methanol. The contents were allowed to dry over night. Finally the material was dried in vacuum oven overnight, to completely remove o-xylene and methanol.

\subsection{Composite moulding and annealing}

Pure PP and PP nanocomposites sheets were compression moulded between steel plates covered with thin Mylar sheets using a hot press at $200^{\circ} \mathrm{C}$ for $5 \mathrm{~min}$. The sheets for the barrier performance tests as well as the composites for structural studies were obtained from the above-mentioned method. Cold circulated water was used to cool the platens to ambient temperature while full pressure was maintained. The average thickness of the composites was $1.5 \mathrm{~mm}$ for wide-angle X-ray scattering (WAXS) and Transmission Electron Microscopy (TEM) studies, and $0.5 \mathrm{~mm}$ for oxygen permeability tests. Peterlin et al. have observed that in polyethylene, tortuosity factor increases on annealing at elevated temperatures, despite an increase in crystallinity [30]. Similar results were observed by other authors [31-33]. Kastura et al. suggested that on annealing PP, there was a reduction of volume due to increased density [23]. Crystallization can be considered to be associated with the formation of thick lamellas with a high concentration of intralamellar imperfections. The presence of intralamellar defects or voids within the lamellar boundaries will lead to an increase in permeability. In order to standardize the effect of crystallisation on the permeability and to reduce the defects within the lamellar boundaries, all nanocomposites (including pure PP film) studied in this research were annealed at higher temperature. Oxygen permeability test sheets were annealed at $75^{\circ} \mathrm{C}$ for $8 \mathrm{~h}$ and kept at room temperature for $24 \mathrm{~h}$ in order to increase the crystallinity.

\subsection{Wide-angle $X$-ray scattering}

WAXS is one the methods for characterising the state of intercalation and exfoliation of clay gallery layers $[2,10,16]$. X-ray data on the treated clay composites was collected on a Bruker AXS D8 Advance wide-angle $\mathrm{X}$-ray diffraction instrument at $45 \mathrm{kV}$ and $30 \mathrm{~mA}$. The composite was mounted in a flat-plate specimen holder with exposed surface flattened with a glass microscope slide. Diffraction patterns were measured using a scintillation detector. Scans were taken between 2 and $25^{\circ}$ at a speed of $1 \% \mathrm{~min}$, a step size of $0.05^{\circ}$ and step time of $3 \mathrm{~s}$ [26].

\subsection{Transmission electron microscopy}

The second most common technique for morphological characterisation of nanocomposites is TEM $[2,10,16]$. TEM technique is widely used to study and assess the dispersion of clay in the PP matrix $[11,17]$. TEM images were obtained via a Philips CM200UT (FEI Co., Hillsboro, OR) operated at a voltage of $80 \mathrm{kV}$. The hot pressed films described previously were embedded in an epoxy compound (dried in vacuum oven at $60^{\circ} \mathrm{C}$, for $24 \mathrm{~h}$ ). The embedded films were then thinly sliced $(\sim 100 \mathrm{~nm})$ using RMC MTX ultramicrotome (UMT, Boeckeler Instrument Inc., Tucson, AZ). The thickness of the thin slice was automatically controlled to be about $50 \mathrm{~nm}$ by ultramicrotome. The thin slice obtained was collected onto a 300 mesh copper grid. Finally, the specimens were characterized by TEM.

\subsection{Oxygen permeability measurements}

The device employed was a Mocon Ox-Tran 2/21 manufactured by Modern Controls Inc. The method was based on ASTM standard D3985 [1, 3]. It has been widely used to analyse the gas barrier proper- 
ties of polymer films [9, 10, 25]. The Modern Controls Inc (Mocon) technical manual explained that Mocon Ox-Tran 2/21 system uses a patented coulometric sensor (coulox) to detect oxygen transmission through both flat materials and packages [34]. The coulox sensor is an intrinsic or absolute sensor that does not require calibration, however the instrument requires calibration using standards provided. The instrument was calibrated at $23^{\circ} \mathrm{C}$ with National Institute of Standards and Technology (NIST) certified Mylar films of known transport characteristics. A continuous flow of gas was maintained on both sides of the barrier material. Initially nitrogen gas was passed over both surfaces to remove oxygen from the film. The nitrogen on one side was then replaced by oxygen, and the nitrogen flow on the other side then swept the surface to extract any oxygen that diffused through the material. The diffusing oxygen was measured by a detector that is sensitive specifically to oxygen. PP and PP nanocomposites were measured only after checking the accuracy of the standards. Flat films were clamped into the diffusion cell that was purged of residual oxygen using an oxygen-free air carrier gas. The carrier gas was routed to the sensor until a stable zero was established. Pure (99.9\%) oxygen was then introduced into the outside chamber of the diffusion cell. Molecules of oxygen diffusing through the film to the inside chamber were conveyed to the sensor by the carrier gas. The test sheets were laminated between two aluminium foil masks to reduce the area of exposure from 100 to $5.4 \mathrm{~cm}^{2}$. Measurements were conducted at $23^{\circ} \mathrm{C}$ and $0 \% \mathrm{RH}$. Three different films were tested for each proportion of clay.

\subsection{Gas tortuous theory}

According to this theory, the impermeable inorganic filler in the relatively permeable polymer
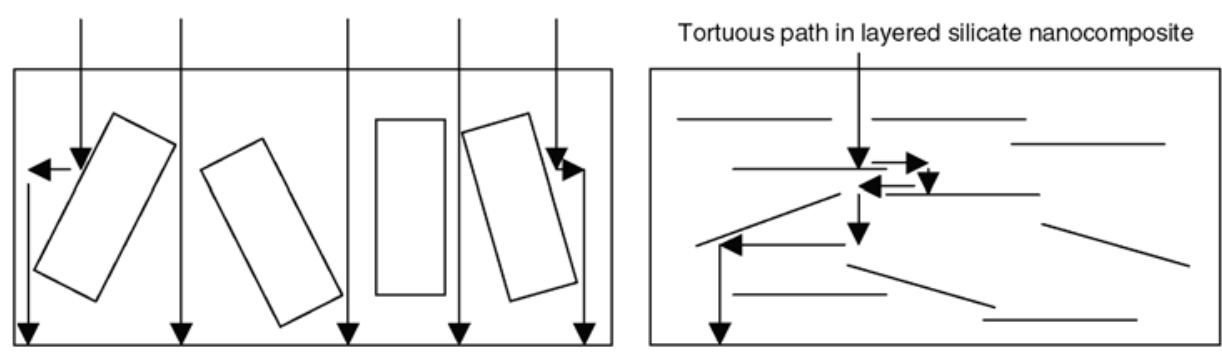

Figure 4. Schematic representation of gas permeation through conventional microcomposite (left) and layered silicate nanocomposite (right) 


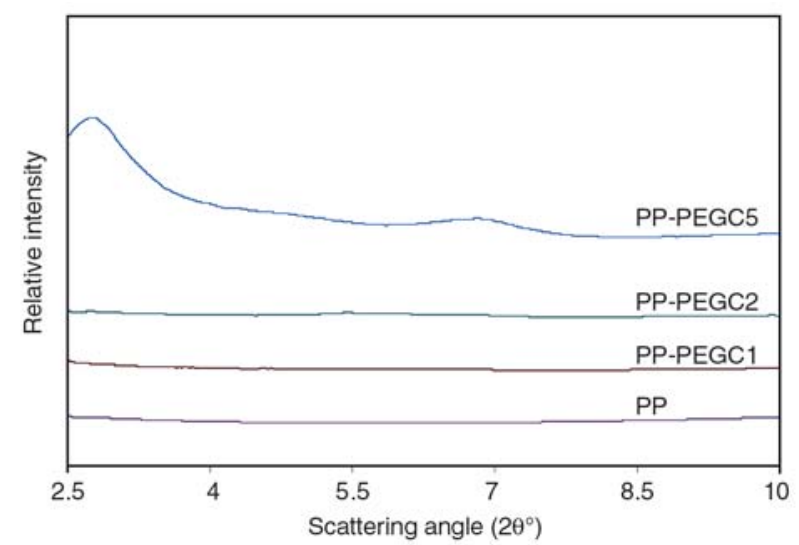

Figure 5. WAXS pattern of pure PP and PP nanocomposites

representative morphological features of the PP and clay state. Of all the six patterns obtained from each composite, the data with maximum intensity and peak formation is shown here. This was to obtain representative view on the composite morphological characteristics and to evaluate attainment of exfoliation (diffraction pattern is featureless in clay sensitive region) or intercalation in the low scattering angle region of 2.5 to $5.5^{\circ}$.

In the current system PEG-ML was used as intercalate for the clay. PEG-ML had molecular weight $\left(M_{n}=400 \mathrm{~g} / \mathrm{mol}\right)$ that is capable of entering the silicate galleries as demonstrated in Figure 3. The scattering pattern for 1 and $2 \mathrm{phr}$ ratios indicate an exfoliated structure was obtained for the treated clay. This is attributed to the treatment facilitating PP insertion into the silicate galleries promoting delamination of the periodic layered structure of the clay. The phase morphology was correlated with the structure observed by TEM. Figures 6 and 7 show the 1 and 2 phr nanocomposites. The image shows individual silicate layers of thickness in the order of a nanometer with aspect ratio in the range of 100 to $250 \mathrm{~nm}$. The exfoliated morphology was due to a lower filler concentration, high-shear dispersion and compatibilization with PP-g-MA. In the ultimate platelet configuration, the clay was completely dispersed and fully exfoliated, resulting in the specific surface at its maximum. This has been achieved for the 1 and 2 phr nanocomposites. Varela et al. suggested that greatest extent of exfoliation was obtained with $40 \%$.wt PP-g-MA, where MA promoted exfoliated morphologies consisting of individual nanometer thick silicate layers suspended in PP matrix (penetration of PP chains

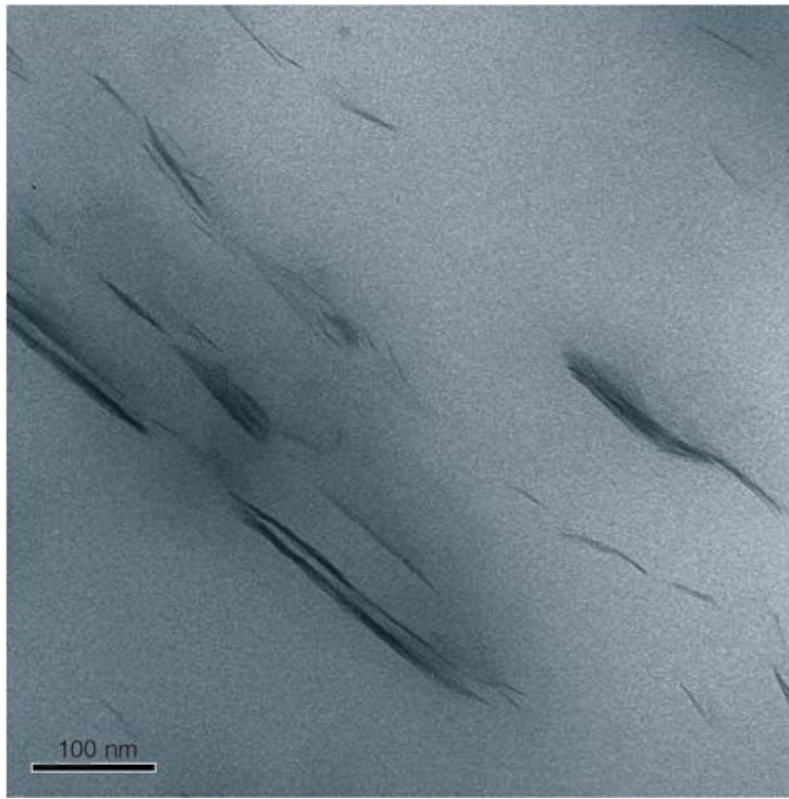

Figure 6. TEM patterns of polypropylene nanocomposites with 1 phr clay

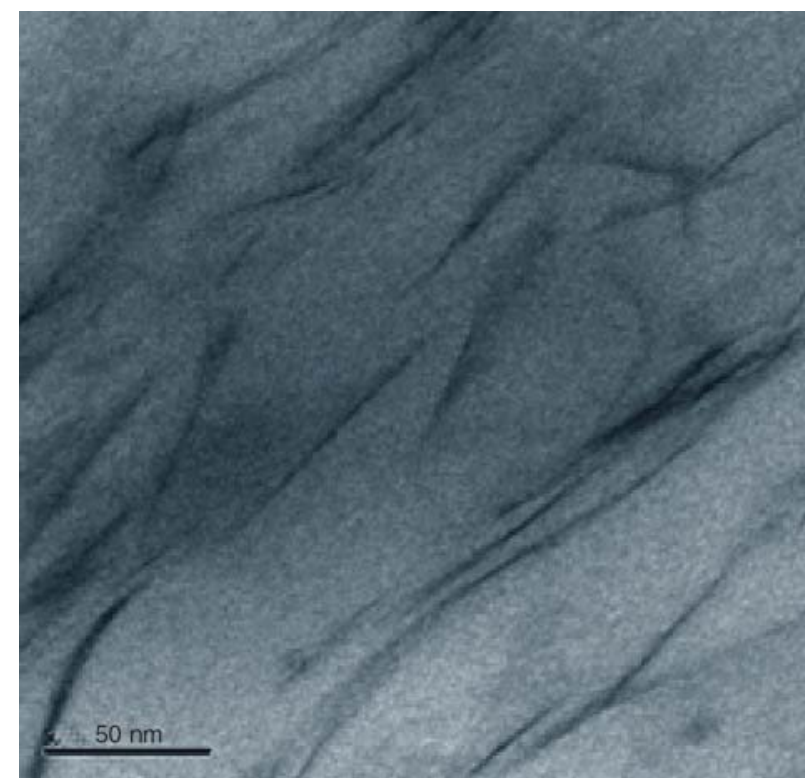

Figure 7. TEM pattern of polypropylene nanocomposites with 2 phr clay

within and delamination of the crystallites) [37]. The interaction between PP and PEGC treated clay was expected to be due to the presence of the long alkyl chain of PEGC and PP-g-MA. A lower (001) diffraction signal intensity was related to a higher extent of platelet exfoliation that occurred during synthesis and processing of the nanocomposite. Sinha Ray et al. suggested that polymer intercalation proceeded from the primary clay particle edges towards the particle center [10]. Complete nanolayer separation required favourable polymer-clay 
interactions to overcome the penalty of polymer confinement.

At higher clay loading of $5 \mathrm{phr}$, a small peak was present at $5.5^{\circ}$ in the diffraction pattern that was due to the attainment of intercalation rather than exfoliation of clay layers (Figure 5). TEM shows the complex morphological features of the clay state. The appearance of individual clay layers is evident, but there are regions containing platelets that have not separated giving rise to a periodicity in structure and hence a diffraction peak. Although the specimens were prepared with solvent, with ultrasonication to facilitate the intercalation, full exfoliation was not achieved. It was noted that the mass transport of highly viscous resin into the clay galleries presents a limitation. This step is considered as one of the important limiting factors for clay platelet separation. In addition, the relative amount of clay platelet separation and aggregation depended on the mixing technique and surfactant used for modifying the clay. In the case of the $5 \mathrm{phr}$ composite, a combination of effects gave rise to the observed structure, such as limited intercalation at a relatively high content of clay, shearing facilitation to disrupt larger agglomerates and overcome incompatibility of clay tactoids. The size of clay lamella observed for PEG-dispersed PP nanocomposite was a reasonable match for the size dimension obtained previously in TEM studies of nanocomposites [16, 38, 39]. Figures 6 and 7 show the exfoliated lamellae, tactoids composed of a variable number of lamella and aggregates of tactoids. Clay ratios ( 1 and 2 phr) showed more uniform distribution of silicate layer without clay aggregates. Higher magnification $(100 \mathrm{~nm})$ clearly displays that clay layers are homogeneously dispersed in the PP matrix, except for $5 \mathrm{phr}$ clay ratios. For $5 \mathrm{phr}$ clay ratio, the intercalated silicate layers are locally stacked to a hundred nanometres in thickness and from several hundred nanometres to more than one micrometer in length [39]. The aspect ratio of clay inclusions can be inferred from the length and thickness of the dark lines in TEM micrographs at different magnifications. Most clay particles were well dispersed in PP matrix, which was due to good compatibility between PP, PP-g-MA and end alkyl chain of treated clay (monolaurate chain of PEG). Avella et al. prepared exfoliated PP based nanocomposites by solution blending [40], similarly from their observations, exfoliation of clay layers

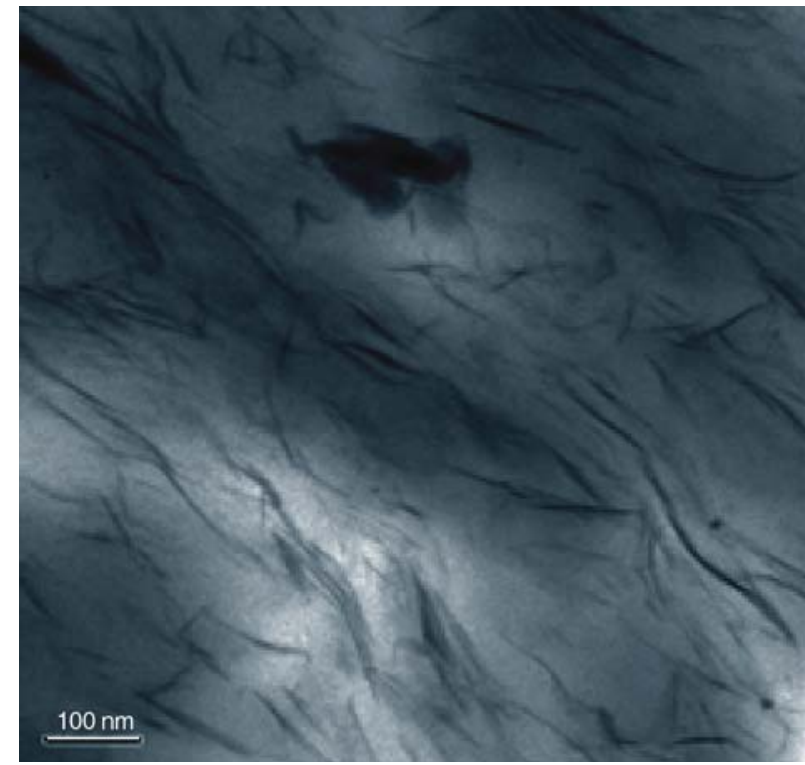

Figure 8. TEM pattern of polypropylene nanocomposites with 5 phr clay

in nanocomposites occurred only at 1 and $3 \%$ wt of clay loading, not at $5 \%$ wt clay. In the $5 \%$ wt nanocomposites (Figure 8). Some clay layers collapsed leading to a tactoid system. Sinha Ray et al. suggested that polymer intercalation proceeded from the primary clay particle edges towards particle centres [10]. Mass transport into the primary particles was found to be the limiting step for nanocomposite formation, the degree of constituent mixing was critical for rapid nanocomposite formation. Shear processing, such as with an ultrasonicator, parallel plate rheometer, conventional compounding equipment, high-shear mixer, decrease the nanocomposite formation time by disruption of primary particles and establishment of composite uniformity. Ultraturrax mixing was sufficient to disperse the clay layers. From our previous study utilizing a polyether of higher molecular weight $\left(M_{n}=600 \mathrm{~g} / \mathrm{mol}\right)$ for clay treatment prior to preparation of nanocomposites using solution blending, we obtained exfoliated structure with 1,2 and $5 \mathrm{phr}$ clay ratios [39].

Mass transport into the primary particles was found to be a limiting step for nanocomposite formation, with the degree of constituent mixing being critical for rapid nanocomposite formation. Shear processing with ultrasonication or conventional compounding equipment will decrease the nanocomposite formation time by disruption of primary particles and establishing composite uniformity [10]. Disappearance of peaks in clay PP composites sug- 
gests two conclusions: 1. Exfoliation - separation of clay lamella into individual clay layers. 2. Agglomeration - clustering of clay gallery layers, undisturbed by shearing action. Moad et al. suggested that the clay layers exfoliated in the presence of PEO based surfactants in the preparation of PP nanocomposites [16]. The authors melt intercalated untreated clay with PEO based surfactants for preparation of PP nanocomposites. Shearing action of the extruder assisted exfoliation of clay layers without use of compatibilizer. Chiu et al. suggested that Cloisite 30B filled polymer nanocomposites will not exfoliate with PP-g-MA because of the higher polarity of Cloisite 30B [41]. The same authors demonstrated exfoliation with poly(styreneco-maleic-anhydride) (PS-g-MA) oligomer as compatibilizer instead of PP-g-MA. The higher polarity of PS-g-MA resulted in exfoliation. Clay interlayer expansion depends on compatibility between polymer and organic intercalant and interactions between the two phases [24]. MMT clay is composed of regularly arranged tactoids and galleries. The length of an organic modifier (in this case: the long alkyl chain of monolaurate) and CEC are two parameters that determine how the chains pack between the silicate layers. Montmorillonite has both surface and edge charges [2]. The charges on the edges are easily accessible to modification, but they do not accomplish much improvement in interlaminar separation. These sites represent an opportunity for attachment of functional groups such as maleic anhydride. PP-g-MA increased both the compatibility and chemical interaction between the polymer and treated clay. This was a reason for exfoliation of clay lamella. Ultraturrax high-shear dispersion and PP-g-MA compatibilizer addition along with long alkyl chain for compatibility with $\mathrm{PP}$ were reasons for exfoliation of clay layers in the PP matrix. Ultraturrax high-shear dispersion lead to exfoliation of the clay layers, for researchers elsewhere $[42,43]$.

\subsection{Oxygen permeability}

Nanocomposites are a multiphase system in which the coexistence of phases with different sorption and diffusion can cause complex transport phenomena [35]. Montmorillonite gives rise to superficial adsorption and specific interactions with some gases and solvents $[10,40]$. The presence of silicate layers are expected to cause a decrease in permeability of oxygen because of more tortuous paths for the diffusing molecules that must bypass impenetrable platelets (Figure 4). This phenomenon is significant when the filler is of nanometer size with high aspect ratio. Avella et al. suggested that nanofillers (calcium carbonate) reduce the permeability to both oxygen and carbon dioxide, and claimed that the nanofillers were responsible for higher barrier properties improvement [11]. It should be noted that nano-sized calcium carbonate are spherical in shape. MMT clay layers can be exfoliated or delaminated into nanometer platelets with a thickness of about $1 \mathrm{~nm}$ and an aspect ratio of 100-1500 and surface areas of 700-800 $\mathrm{m}^{2} / \mathrm{g}$. Each platelet has high strength and stiffness and can be regarded as a rigid inorganic polymer whose molecular weight $\left(10^{8} \mathrm{~g} / \mathrm{mol}\right)$ is much greater than that of typical polymers. Therefore, low fractions of clays are required to achieve equivalent properties compared with conventional composites (calcium carbonate). It was deduced that with increasing clay content in a nanocomposites, the permeability of gases was reduced. This was the case for the composites in this research.

Table 2 lists the oxygen permeability for nanocomposites while Figure 9 graphically shows the permeability versus clay content. It can be seen that the permeability of oxygen decreased with increase in clay ratio. The $1 \mathrm{phr}$ composition showed marginal reduction $(\sim 3 \%)$, but $2 \mathrm{phr}$ reduced permeability about $20 \%$ compared with the PP matrix. The oxygen permeability of $5 \mathrm{phr}$ clay composite reduced by almost $30 \%$. The clay layers themselves are impervious to oxygen, providing barrier resistance. The volume occupied by the clay and amount of clay influenced the actual three-dimensional arrangement and dispersion. At low concentrations, permeability decrease was not significant indicating there was insufficient platelets to provide resistance to permeability and the torturous path required. The permeability depended on the aspect

Table 2. Oxygen permeability values for PP- PEGC treated clay nanocomposites

\begin{tabular}{|c|c|c|c|c|c|}
\hline \multirow{2}{*}{$\begin{array}{c}\text { PEGC } \\
{[\mathrm{phr}]}\end{array}$} & \multicolumn{4}{|c|}{$\begin{array}{l}\text { Oxygen permeability } \\
{\left[\mathrm{cm}^{3} \cdot \mathrm{mm} / \mathrm{m}^{2} \cdot \text { day } \cdot \text { atm }\right]}\end{array}$} & \multirow{2}{*}{$\begin{array}{l}\text { Standard } \\
\text { deviation }\end{array}$} \\
\hline & Sample 1 & Sample 2 & Sample 3 & Average & \\
\hline 1 & 90.0 & 91.1 & 89.9 & 90.2 & 0.8 \\
\hline 2 & 74.0 & 71.4 & 75.2 & 73.5 & 1.9 \\
\hline 5 & 65.1 & 70.9 & 69.8 & 68.6 & 3.1 \\
\hline
\end{tabular}




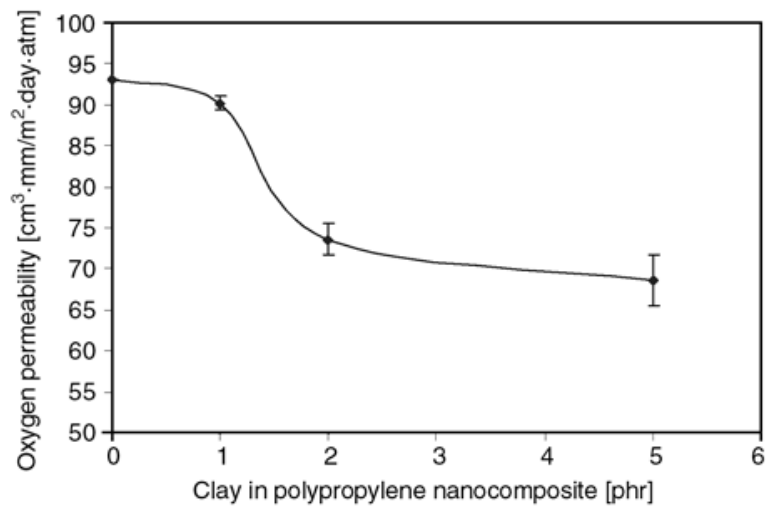

Figure 9. Oxygen permeability of polypropylene nanocomposites with 1,2 and 5 phr clay

ratio of the clay layers. Dispersion of clay ranged from intercalation, exfoliation and agglomeration of clay layers at $5 \mathrm{phr}$ clay loadings. The effects of nano-filler in a polymer material depend principally on six factors; 1 . properties relative to the polymer, 2. concentration (volume fraction), 3. size distribution, 4 . shape and distribution of shapes and 5. degree of dispersion 6. adhesion to the polymer matrix. Since there are a number of factors to assess for a polymer nanocomposite, barrier property enhancement in nanocomposites can be applied to validate the dispersion of fillers in a polymer matrix [44]. The change in oxygen permeability of nanocomposites was controlled by the clay content and microstructure. Tactoids at low clay ratios (1 and 2 phr) exfoliated better than those at high clay ratio (5 phr). The deviation of oxygen permeability increased with clay ratios, indirectly supported by the WAXS and TEM results. Lohfink et al. suggested that the oxygen permeability of PP-g-MA was greater than pure PP [45], although it should be noted that $10 \%$ of PP-g-MA was present in their nanocomposites.

\section{Conclusions}

The aim was to obtain MMT with a modified surface featuring hydrophobicity and increased affinity with PP. The prospect of developing layered silicates such as MMT as a multifunctional additive for PP at less than 5\% wt was satisfactory using solution blending. Nanocomposites prepared using PEG-ML treated clay in ratios of 1, 2 phr exfoliated well in a matrix of PP blended with PP-g-MA, with an exception of agglomerate formation for $5 \mathrm{phr}$ clay loading. Diffraction patterns suggested exfoli- ation of clay layers in the PP nanocomposites. The diffraction patterns cannot be used alone to adequately describe nanoscale dispersion of the layered silicate. Interpretation of the structure and clay state was validated with morphological observation using TEM. The actual nanoscale dispersion and overall global dispersion of the clay in PP was revealed and nanocomposites with low loading (1 and $2 \mathrm{phr}$ ) formed exfoliated clay layers. The $5 \mathrm{phr}$ clay composition, revealed that clay layers dispersed uniformly in the matrix, although some clusters or agglomerated particles were detected leading to the diffraction peaks observed using WAXS. These clusters could be due to clay undisturbed by high-shear dispersion. Clay dispersion increased the barrier properties by creating a tortuous path to limit the progress of oxygen molecules through the PP matrix. While a low loading $1 \mathrm{phr}$ showed an exfoliated structure, the amount was not sufficient to adequately reduce the oxygen permeability. The $2 \mathrm{phr}$ provided improved resistance by increasing the barriers for oxygen molecules to diffuse around. This suggested a threshold was obtained with exfoliated structures. At $5 \mathrm{phr}$, the conditions employed to prepare the nanocomposites or the volume fraction of clay particles was insufficient to allow efficient exfoliation and dispersion of the clay. Oxygen permeability for hybrids with clay loadings to $5 \mathrm{phr}$ was less than the corresponding values for pure PP, indicating that platelet structure and dispersion were important in obtaining permeability reduction.

\section{Acknowledgements}

Authors would like to thank Mr. Ashfaqar Rahaman, Mr. Frank Antolasic, Mr. Karl Lang, Ms. Nadia Zartack, and Dr. Mohammed Al Kobaisi of RMIT University for their valuable suggestions.

\section{References}

[1] Massey L.: Permeability properties of plastics and elastomers. William Andrew Publishing/Plastics Design Library, New York (2003).

[2] Utracki L. A., Sepehr M., Boccaleri E.: Synthetic, layered nanoparticles for polymeric nanocomposites (PNCs). Polymers for Advanced Technologies, 18, 137 (2007).

[3] Karian H. G.: Handbook of polypropylene and polypropylene composites. Marcel Dekker, New York (2003). 
[4] Vasile C.: Handbook of polyolefins. Marcel Dekker, New York (2000).

[5] Lange J., Wyser Y.: Recent innovations in barrier technologies for plastic packaging- A review. Packaging Technology and Science, 16, 149-158 (2003).

[6] Osborn K. R., Jenkins W. A.: Plastic films: Technology and packaging applications. CRC Press, Boca Raton (1992).

[7] Faisant J., Ait-Kadi A., Bousmina M., Deschenes L.: Morphology, thermomechanical and barrier properties of polypropylene-ethylene vinyl alcohol blends. Polymer, 39, 533-545 (1998).

[8] Osman M. A., Mittal V., Lusti H. R.: The aspect ratio and gas permeation in polymer-layered silicate nanocomposites. Macromolecular Rapid Communications, 25, 1145-1149 (2004).

[9] Osman M. A., Atallah A.: High-density polyethylene micro- and nanocomposites: Effect of particle shape, size and surface treatment on polymer crystallinity and gas permeability. Macromolecular Rapid Communications, 25, 1540-1544 (2004).

[10] Sinha Ray S., Okamoto M.: Polymer/layered silicate nanocomposites: A review from preparation to processing. Progress in Polymer Science, 28, 1539-1641 (2003).

[11] Avella M., Cosco S., Di Lorenzo M., Di Pace E., Gentile G., Errico M.: iPP based nanocomposites filled with calcium carbonate nanoparticles: Structure/properties relationships. Macromolecular Symposia, 234, 156-162 (2006).

[12] Yano K., Usuki A., Okada A.: Synthesis and properties of polyimide-clay hybrid films. Journal of Polymer Science, Part A: Polymer Chemistry, 35, 22892294 (1997).

[13] Grim R. E.: Clay mineralogy. McGraw-Hill, New York (1953).

[14] Theng B. K. G.: The Chemistry of clay-organic reactions. John Wiley and Sons, New York (1974).

[15] Ton-That T-M., Perrin-Sarazin F., Cole K. C., Bureau M. N., Denault J.: Polyolefin nanocomposites: Formulation and development. Polymer Engineering and Science, 44, 1212-1219 (2004).

[16] Moad G., Dean K., Edmond L., Kukaleva N., Li G., Mayadunne R. T. A., Pfaendner R., Schneider A., Simon G. P., Wermter H.: Non-ionic, poly(ethylene oxide)-based surfactants as intercalants/dispersants/ exfoliants for poly(propylene)-clay nanocomposites. Macromolecular Materials and Engineering, 291, 3752 (2006).

[17] Kooli F., Magusin P. C. M. M.: Adsorption of cetyltrimethylammonium ions on an acid-activated smectite and their thermal stability. Clay Minerals, 40, 233-243 (2005).

[18] Pannirselvam M., Gupta R. K., Shanks R. A., Bhattacharya S. N.: Polypropylene clay nanocomposites prepared with polyether intercalated clay. in 'Proceedings of PPS-23, El Savador, Brazil', paper number: 087 (2007).
[19] Yao H., Zhu J., Morgan A. B., Wilkie C. A.: Crown ether-modified clays and their polystyrene nanocomposites. Polymer Engineering and Science, 42, 1808 1814 (2002).

[20] Aranda P., Ruiz-Hitzky E.: Poly (ethylene oxide)-silicate intercalation materials. Chemistry of Materials, $\mathbf{4}$, 1395-1403 (1992).

[21] Ruiz-Hitzky E., Aranda P.: Polymer-salt intercalation complexes in layer silicates. Advanced Materials, 2, 545-547 (1990).

[22] Tunney J. J., Detellier C.: Aluminosilicate nanocomposite materials. Poly(ethylene glycol)-kaolinite intercalates. Chemistry of Materials, 8, 927-935 (1996).

[23] Katsura T., Kamal M. R., Utracki L. A.: Some properties of polypropylene filled with metal fibers. Polymer Composites, 6, 282-295 (1985).

[24] Velasco J. I., Ardanuy M., Realinho V., Antunes A. I., Fernández J. I., González-Peña M. A., RodríguezPérez J. A.: Polypropylene/clay nanocomposites: Combined effects of clay treatment and compatibilizer polymers on the structure and properties. Journal of Applied Polymer Science, 102, 1213-1223 (2006).

[25] Leuteritz A., Pospiech D., Kretzschmar B., Willeke M., Jehnichen D., Jentzsch U., Grundke K., Janke A.: Progress in polypropylene nanocomposite development. Advanced Engineering Materials, 5, 678-681 (2003).

[26] Pannirselvam M., Gupta R. K., Bhattacharya S. N., Shanks R. A.: Intercalation of montmorillonite by interlayer adsorption and complex formation. Advance Materials Research, 29-30, 295-298 (2007).

[27] Lee E. C., Mielewski D. F., Baird R. J.: Exfoliation and dispersion enhancement in polypropylene nanocomposites by in-situ melt phase ultrasonication. Polymer Engineering and Science, 44, 1773-1782 (2004).

[28] Zhang Y-Q., Lee J-H., Jang H-J., Nah C-W.: Preparing PP/clay nanocomposites using a swelling agent. Composites, Part B: Engineering, 35, 133-138 (2004).

[29] Manias E., Touny A., Wu L., Strawhecker K., Lu B., Chung T. C.: Polypropylene/montmorillonite nanocomposites. Review of the synthetic routes and materials properties. Chemistry of Materials, 13, 35163523 (2001).

[30] Peterlin A.: Dependence of diffusive transport on morphology of crystalline polymers. Journal of Macromolecular Science, Part B: Physics, 11, 57-87 (1975).

[31] Vieth W.: Diffusion in and through polymers: Principles and applications. Hanser, New York (1991).

[32] Vittoria V., Perullo A.: Effect of quenching temperature on the structure of isotactic polypropylene films. Journal of Macromolecular Science, Part B: Physics, 25, 267-281 (1986).

[33] Vieth W., Wuerth W. F.: Transport properties and their correlation with the morphology of thermally conditioned polypropylene. Journal of Applied Polymer Science, 13, 685-712 (1969).

[34] Modern Controls Inc.: Technical manual for Ox-Tran, 2/21, 1-11 (2006). 
[35] Gorrasi G., Tammaro L., Mariarosaria T., Vittoria V., Kaempfer D., Reichert P., Mülhaupt R.: Transport properties of organic vapors in nanocomposites of isotactic polypropylene. Journal of Polymer Science, Part B: Polymer Physics, 41, 1798-1805 (2003).

[36] Meille S., Bruckner S., Porzio W.: Isotactic polypropylene. A structure with nonparallel chain axes. Macromolecules, 23, 4114-4121 (1990).

[37] Varela C. R., Rosales C., Perera R., Matos M., Poirier T., Blunda A., Rojas H.: Functionalized polypropylenes in the compatibilization and dispersion of clay nanocomposites. Polymer Composites, 27, 451-460 (2006).

[38] Pannirselvam M., Gupta R. K., Shanks R. A., Bhattacharya S. N.: Synthesis of a novel compatibilizer for polypropylene clay nanocomposites. in 'Proceedings of Chemeca-2007, Melbourne, Australia', 1705-1711 (2007).

[39] Pannirselvam M., Ivanov I., Shanks R. A., Bhattacharya S. N.: Composition and mechanical properties of polypropylene polyether treated clay nanocomposites. in 'Proceedings of Chemeca-2007, Melbourne, Australia', 130-135 (2007).

[40] Avella M., Simona C., Gaetano D. V., Errico M. E.: Crystallization behavior and properties of exfoliated isotactic polypropylene/organoclay nanocomposites. Advances in Polymer Technology, 24, 132-144 (2005).
[41] Chiu F-C., Lai S-M., Chen J-W., Chu J-W.: Combined effects of clay modifications and compatibilizers on the formation and physical properties of melt-mixed polypropylene/clay nanocomposites. Journal of Polymer Science, Part B: Polymer Physics, 42, 4139-4150 (2004).

[42] Rhoney I., Brown S., Hudson N. E., Pethrick R. A.: Influence of processing method on the exfoliation process for organically modified clay systems. I. Polyurethanes. Journal of Applied Polymer Science, 91, 1335-1343 (2004).

[43] IJdo W. L., Kemnetz S., Benderly D.: An infrared method to assess organoclay delamination and orientation in organoclay polymer nanocomposites. Polymer Engineering and Science, 46, 1031-1039 (2006).

[44] Bhattacharya S. N., Gupta R. K., Kamal M. R.: Polymer nanocomposites: Theory and practice. Hanser Gardner, Munich (2007).

[45] Lohfink G. W., Kamal M. R.: Morphology and permeability in extruded polypropylene/ethylene vinyl-alcohol copolymer blends. Polymer Engineering and Science, 33, 1404-1420 (1993). 